\title{
Modelagem matemática aplicada à migração de substâncias em embalagens plásticas de alimentos
}

\author{
Gilmar de Oliveira Veloso Vanessa Schuh* \\ Instituto Federal Catarinense Câmpus Concórdia, IFC - Câmpus Concórdia/SC \\ 89700-000, Concórdia, SC \\ E-mail: gilmar.veloso@ifc-concordia.edu.br \\ E.mail: vanessa_pzo@hotmail.com
}

\section{RESUMO}

Este trabalho resolve a equação de difusão de massa utilizando o método de Crank-Nicolson. O objetivo deste trabalho é aplicar a equação de difusão de massa em problemas de embalagens plásticas de alimentos para a determinação do perfil de concentração das substâncias migrantes em embalagens ativas a fim de compreender o processo de difusão de componentes.

O controle do processo de migração de componentes químicos presentes nas embalagens tem despertado interesse de diversos setores a fim de evitar a contaminação química. A migração é usualmente mensurada através de importantes técnicas experimentais, normalmente caras e trabalhosas.

A modelagem matemática e simulação numérica têm por objetivo principal, como ferramenta para o desenvolvimento dos processos em embalagens ativas, prever comportamentos dinâmico e estacionário do processo difusivo.

Com o intuito de contribuir com este importante tema, é apresentado um modelo matemático e aplicativo para estudar o comportamento do processo de difusão em embalagens plásticas. O modelo transiente e unidimensional na variável espacial é baseado na equação de difusão de massa com coeficiente de difusão, nesta etapa do projeto, constante, dada como:

$$
\frac{\partial C_{A}}{\partial t}=D_{A B} \frac{\partial^{2} C_{A}}{\partial x^{2}}
$$

sujeita a condição inicial $C(x, 0)=C_{0}$

e condições de contorno: $\frac{\partial C_{A}}{\partial x}(0, t)=0 \mathrm{e} \frac{\partial C_{A}}{\partial x}(l, t)=0$

onde $C_{A}$ é a concentração da substância migrante [adimensional], $D_{A B}$ é o coeficiente de difusão do migrante $A$ para o meio simulante $B, t$ é a variável temporal $[\mathrm{s}]$ e $x$ é a variável espacial $[\mathrm{m}]$

A equação de difusão foi discretizada pelo método de diferenças finitas, centrada na variável temporal, com uma malha de espaçamento constante na variável espacial. O método numérico utilizado é o método implícito de Crank-Nicolson e o sistema de equações tridiagonal gerado é resolvido pelo algoritmo de Thomas. O aplicativo foi desenvolvido em linguagem de programação Python. Como resultado, espera-se obter o perfil das concentrações de substâncias migrantes das embalagens em relação ao tempo e em relação a espessura da embalagem plástica.

Palavra-chave: Migração, Embalagem plástica, Simulação numérica, Diferenças finitas, Crank-Nicolson. 


\section{Referências}

[1] A. Bejan, "Transferência de calor”, Editora Edgard Blücher Ltda, pp. 540, São Paulo, 1996.

[2] M. C. C. Cunha, "Métodos Numéricos", Editora UNICAMP, 2edição, Campinas, SP, 2003.

[3] P. Suppakul, K. Sonneveld, S. W. Bigger, J. Miltz, Diffusion of linalool and methylchavicol from polyethylene-basead antimicrobial packaging films, LWT, vol. 44, pp. 1888-1893, (2011). 